УДК 519.711

Борис Леонідович Бутвін (доктор технічних наук, професор)

Олександр Олександрович Машкін (кандидат технічни наук, с. н. с.)

Олексій Іванович Соломицький (кандидат військових наук, с. н. с.)

Центральний науково-дослідний інститут Збройних Сил Украӥни, Київ, Украӥна

\title{
ВИКОРИСТАННЯ МОДИФІКОВАНИХ РІВНЯНЬ ДИНАМІКИ СЕРЕДНІХ ДЛЯ ОПЕРАТИВНОГО ПРОГНОЗУВАННЯ ХОДУ ТА РЕЗУЛЬТАТІВ БОЙОВИХ ДІЙ
}

\begin{abstract}
Стаття присвячена розгляду особливостей використання рівнянь динаміки середніх для оперативного прогнозування ходу та результатів бойових дій. Різні топологї рівнянь Ланчестера можуть бути використані в якості інструменту прогнозних розрахунків, приймаючи до уваги оперативність отримання результатів та ясний фізичний зміст складових таких рівнянь. Але, до важливих обмежень моделей динаміки середніх слід віднести припущення про однорідність складу протиборчих угруповань. Неоднорідність складу угруповань, а також змінна інтенсивність надходження резервів до угруповань протягом бойових дій можуть бути ураховані иляхом варіювання відповідних коефіцієнтів у складених системах рівнянь. Використання змінних коефіцієнтів у системах диференційних рівнянь в процесі їх чисельного інтегрування потребує оцінювання стійкості отриманих рімень за Ляпуновим. Збереження оперативності здійснення прогнозних розрахунків за модифікованими рівняннями Ланчестера можливо за умови використання сучасних середовищ моделювання 3 реалізованими у них алгоритмами чисельного інтегрування. У статті приведений приклад аналітичного розв'язання системи рівнянь Ланчестера з оиінкою стійкості рішення для постійних коефіцієнтів, а також результати вирішення тісї ж системи чисельним методом у середовищі AnyLogic для постійних та змінних коефіцієнтів інтенсивності поповнення чисельності угруповань. Підтверджена збіжність отриманих результатів дозволила в якості висновку запропонувати використання модифікації систем рівнянь Ланчестера зі змінними коефійєнтами з одночасною оцінкою стійкості їх рішень для наближення такого опису до реалій бойових дій і підвищення достовірності отриманих результатів.
\end{abstract}

Ключові слова: метод динаміки середніх; рівняння Ланчестера; динаміка бойових дій.

Постановка проблеми. Потреба органів військового управління та оперативних штабів різних рівнів у моделях, які дозволяють оперативно та достатньо адекватно прогнозувати можливий хід та результати бойових дій, обумовлює необхідність всебічного розгляду особливостей представників такого широкого класу моделей, якими $\epsilon$ аналітичні моделі. Особливе місце у цьому класі займають так звані моделі «динаміки середніх», побудовані на базі різних модифікацій рівнянь Осипова-Ланчестера $[1,2]$. Регулярна поява публікацій 3 тематики використання означених рівнянь 3 метою оперативного прогнозування можливого ходу та результатів бойових дій свідчить про дієздатність та достатню апробованість такого апарату. Дійсно, до переваг такого підходу можна віднести ясний фізичний зміст складових, які можуть входити у різні модифікації рівнянь (наслідком чого $\epsilon$ можливість зрозумілим чином інтерпретувати отримані результати), оперативність отримання результатів та контрольованість проведення розрахунків. Відносно останніх двох переваг $\epsilon$ необхідним наступне зауваження. Оперативність та контрольованість процесу моделювання за складеними диференційними рівняннями може бути досягнути лише 3 використанням сучасних середовищ моделювання, оскільки більшість варіантів рівнянь Ланчестера 3 урахуванням відновлення (поновлення) озброєння (особового складу), змінної інтенсивності потоків подій (наприклад - уражаючої дії зразків озброєння) або складні для суто аналітичного вирішення, або взагалі його не мають і потребують використання методів чисельного інтегрування складених систем рівнянь.

Кажучи про переваги використання методу динаміки середніх необхідно також зауважити про певні обмеження, обумовлені, насамперед, його марківською природою. Одним з основних таких обмежень можна вважати припущення про однорідність елементів систем, що описуються таким методом. Способи приведення різнорідних угруповань до єдиних, прийнятних для опису рівняннями Ланчестера, достатньо висвітлені у тематичних публікаціях і зводяться, як правило, до використання еталонних (еквівалентних) одиниць, відносно яких нормуються різнорідні угруповання 
(або їх можливості у вигляді бойових потенціалів, [2]). У той же час, можливість використання динамічних коефіцієнтів при фазових змінних у рівняннях Ланчестера, в ролі яких можуть виступати будь-які важливі з точки зору варіації структури та властивостей системи функції, дозволяє певним чином урахувати як неоднорідність протиборчих угруповань, так i змінну інтенсивність надходження резервів (матеріально-технічних засобів) протягом бойових дій. Звісно, застосування функцій, що залежать від часу, в якості коефіцієнтів при фазових змінних або вільних членів у системах диференційних рівнянь, може призвести до переводу їх у розряд нестаціонарних. Але, при використанні, як вже було згадано, сучасних моделюючих середовищ та при достатньому обгрунтуванні такого підходу, це дозволить розширити межі застосування моделей динаміки середніх у практичному плані, що представляється актуальним завданням.

Аналіз останніх досліджень і публікацій. Серед робіт, присвячених розгляду різних топологій ланчестерських моделей та питанням ї практичного використання, можна відмітити публікації [1, 2], у яких достатньо детально висвітлені особливості модифікацій такого роду моделей, а також певні аспекти їх практичного застосування. Проте, поза увагою у відмічених публікаціях залишаються два важливих, на наш погляд, питання: використання змінних коефіцієнтів у рівняннях, про можливість застосування яких відмічалося ще у [3]; та перевірка стійкості рішень, що отримуються за допомогою різновидів рівнянь Ланчестера. Ці питання пов'язані між собою, розгляд такого зв'язку у контексті використання методу динаміки середніх для прогнозування ходу та результатів бойових дій і складає мету статті.

\section{Виклад основного матеріалу дослідження}

Оскільки серед розглянутих джерел публікація [1] присвячена, в основному, огляду особливостей різних топологій моделей Ланчестера, а публікація [2] більше орієнтована на практичне використання моделей за означеною темою статті, саме викладені у [2] варіанти рівнянь можуть бути взяті в якості прикладу для аналізу i розгляду можливості їх використання у певній модифікації.

Розглянемо наступний варіант системи рівнянь динаміки середніх, який передбачає відновлення чисельності угруповань протиборчих сторін ( $x$ та у) в ході бою:

$$
\left\{\begin{array}{ll}
\frac{d x}{d t}=-\lambda_{2} y+\mu_{1}\left(N_{1}-x\right), & x(0)=N_{1} \\
\frac{d y}{d t}=-\lambda_{1} x+\mu_{2}\left(N_{2}-y\right), & y(0)=N_{2}
\end{array},\right.
$$

де $\mathrm{N}_{1,2}$ - початкові чисельності протиборчих угруповань; $\lambda_{1,2}$ - інтенсивності вражаючої дії бойових одиниць сторін;

$\mu_{1,2}$ - інтенсивності відновлення чисельності угруповань.

У [2] автори, посилаючись на складність аналітичного рішення такої системи, відразу переходять до чисельного методу інтегрування, але, у нашому випадку, аналітичне рішення $\epsilon$ необхідним виходячи 3 наступних міркувань. Поперше, це потреба у аналізі стійкості (за Ляпуновим) рішень, отриманих за системою (1); по-друге, це можливість контролю отриманих чисельними методами рішень при варіюванні коефіцієнтів $\lambda_{1,2}$ та $\mu_{1,2}$. Крім цього, у загальному вигляді аналітичне рішення (методом Ейлера) системи (1) було приведено в [4]. Наведемо у дещо скороченому вигляді послідовність розв'язання системи (1) іншим методом (методом виключення) для наступних, взятих довільно, умов:

\begin{tabular}{|l|l|l|l|l|l|}
\hline \multicolumn{3}{|c|}{ Табличя } \\
\hline $\mathrm{N}_{1}=3$ & $\lambda_{1}=2$ & $\mu_{1}=0,3$ & \multicolumn{3}{|c|}{ сторона $y$} \\
\hline
\end{tabular}

За приведених умов передбачається, що сторона $y$, маючи трьохкратну перевагу у початковій кількості деяких приведених (віднормованих) одиниць угруповання, наступає; відповідно сторона $x$ обороняється, при цьому поповнюючи чисельність свого угруповання 3 інтенсивністю $\mu_{1}=0,3$ (приведених одиниць на одиницю часу). Інтенсивності уражаючої дії бойових одиниць сторін ( $\lambda_{1}$ та $\left.\lambda_{2}\right)$ вважаються незмінними та відповідають приведеним в табл. 1 .

Тоді система (1) приймає вигляд:

$$
\left\{\begin{array}{ll}
\frac{d x}{d t}=-0,3 x-3 y+0,9, & \mid x(0)=3 \\
\frac{d y}{d t}=-2 x, & \mid y(0)=9
\end{array} .\right.
$$

Використовуючи метод виключення, отримуємо:

$$
\begin{aligned}
x & =-0,5 \frac{d y}{d t}, \\
\frac{d x}{d t} & =-0,5 \frac{d^{2} y}{{d t^{2}}^{2}} .
\end{aligned}
$$

Відповідно, маємо лінійне неоднорідне рівняння другого порядку 3 постійними коефіцієнтами:

$$
\frac{d^{2} y}{d^{2}}+0,3 \frac{d y}{d t}+6 y=1,8 .
$$

Характеристичне рівняння та його корені мають вигляд

$$
\left\{\begin{array}{l}
\mathrm{k}^{2}+0,3 \mathrm{k}+6=0, \\
\mathrm{D}=-23,91 \rightarrow \mathrm{k}_{1,2}=\frac{-0,3 \pm \sqrt{-23,91}}{2}= \\
=-0,15 \pm 2,44 \mathrm{i} .
\end{array}\right.
$$

Цей момент заслуговує на увагу зважаючи на наступне. Використання (цілком виправдане) 
чисельних методів інтегрування не дає змоги за отриманими частковими рішеннями судити про характер інших часткових рішень. Іншими словами, якщо розглядати кожне часткове рішення як рух матеріальної точки, у випадку стійкого рішення характер такого руху мало змінюється при незначній зміні початкових умов. Ілюстративно найбільш наглядно це може бути продемонстровано у фазовій системі координат хОу, де початок координат (O) $є$ особливою точкою для сімейства інтегральних кривих (траєкторій руху). У випадку стійкого рішення такі траєкторії будуть необмежено наближатися до особливої точки, а вид траєкторій визначатиметься коренями характеристичного рівняння. Так, у (6) отримані комплексно-споряджені корені 3 від'ємною дійсною частиною, що свідчить про стійкість рішення за Ляпуновим, у фазовій площині хОу інтегральні криві утворюють сімейство логарифмічних спіралей (рис.1), які при $\mathrm{t} \rightarrow \infty$ будуть необмежено наближатися до особливої точки, яка у даному випадку є стійким фокусом.

Після отримання підтвердження стійкості рішення (лише у такому випадку отримані результати заслуговуватимуть на довіру) для використання в подальшому чисельних методів інтегрування системи (2), знайдемо іiі рішення у явному вигляді 3 метою отримання можливості контролю результатів таких методів.

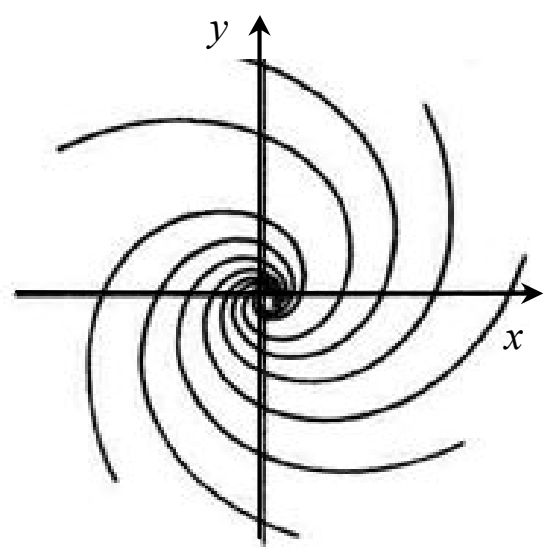

Рис. 1. Особлива точка «стійкий фокус»

Рішення неоднорідного рівняння виду (5) шукається у вигляді суми відповідного загального рішення однорідного рівняння у та деякого часткового рішення $\tilde{\mathrm{y}}$.

Для коренів виду (6) загальне рішення шукається у вигляді:

$$
\mathrm{y}=\mathrm{e}^{-0,15 \mathrm{t}}\left(\mathrm{C}_{1} \cos 2,44 \mathrm{t}+\mathrm{C}_{2} \sin 2,44 \mathrm{t}\right),
$$

часткове рішення для коренів (6) та виду правої частини рівняння (5) шукається у вигляді $\widetilde{\mathrm{y}}=\mathrm{A}$, $\widetilde{\mathrm{y}}^{\prime}=0, \widetilde{\mathrm{y}}^{\prime \prime}=0$.
Загальне рішення неоднорідного рівняння має вигляд

$$
\mathrm{y}=\mathrm{e}^{-0,15 \mathrm{t}}\left(\mathrm{C}_{1} \cos 2,44 \mathrm{t}+\mathrm{C}_{2} \sin 2,44 \mathrm{t}\right)+0,3,
$$

Відповідно для підстановки в (3)

$$
\mathrm{y}^{\prime}=\mathrm{e}^{-0,15 \mathrm{t}}\left[\begin{array}{l}
\left(-0,15 \mathrm{C}_{1}+2,44 \mathrm{C}_{2}\right) \cos 2,44 \mathrm{t}- \\
-\left(2,44 \mathrm{C}_{1}-0,15 \mathrm{C}_{2}\right) \sin 2,44 \mathrm{t}
\end{array}\right] .
$$

Загальне рішення системи ДУ:

$$
\left\{\begin{array}{l}
\mathrm{x}(\mathrm{t})=-0,5 \mathrm{e}^{-0,15 \mathrm{t}}\left[\begin{array}{l}
\left(-0,15 \mathrm{C}_{1}+2,44 \mathrm{C}_{2}\right) \cos 2,44 \mathrm{t}- \\
-\left(2,44 \mathrm{C}_{1}-0,15 \mathrm{C}_{2}\right) \sin 2,44 \mathrm{t}
\end{array}\right] . \\
\mathrm{y}(\mathrm{t})=\mathrm{e}^{-0,15 \mathrm{t}}\left(\mathrm{C}_{1} \cos 2,44 \mathrm{t}+\mathrm{C}_{2} \sin 2,44 \mathrm{t}\right)+0,3
\end{array}\right.
$$

Часткове рішення, що відповідає початковим умовам $\mathrm{x}(0)=3, \mathrm{y}(0)=9$ :

$$
\left\{\begin{array}{l}
\mathrm{x}(0)=0,075 \mathrm{C}_{1}-1,22 \mathrm{C}_{2}=3 \\
\mathrm{y}(0)=\mathrm{C}_{1}+0,3=9 \rightarrow \mathrm{C}_{1}=8,7 \rightarrow \mathrm{C}_{2}=-1,92
\end{array},\right.
$$

остаточно:

$$
\left\{\begin{array}{l}
x(t)=-0,5 e^{-0,15 t}\left(\begin{array}{l}
-5,9898 \cos 2,44 t- \\
-21,516 \sin 2,44 t
\end{array}\right) \\
y(t)=e^{-0,15 t}(8,7 \cos 2,44 t-1,92 \sin 2,44 t)+0,3 .
\end{array}\right.
$$

Отримане рішення системи (2) дозволить порівняти результати аналітичного розв'язання та результати чисельного інтегрування системи виду (1) у середовищі імітаційного моделювання, в якості якого обраний пакет AnyLogic. Середовище AnyLogic, як потужний інструмент досліджень, дозволяє варіювати всі параметри систем рівнянь в процесі їх чисельного рішення. Схема реалізації моделі рівнянь (1) у середовищі AnyLogic представлена на рис. 2, результати розрахунків у вигляді співвідношення чисельності угруповань $y$ до $x(W)$ - на рис. 3. При цьому на рис. 3 наведені зміни залежності $\mathrm{W}$ від параметру $\mu_{1}$, який розглядається як постійний $\left(\mu_{1}=0,1 ; 0,3 ; 0,5\right)$, та як динамічний, що змінюється у діапазоні від 0,5 до 0,1 (інтенсивність відновлення зменшується протягом часу, такому варіанту відповідає позначення $\mu_{\mathrm{var}}$, рис. 3 ).

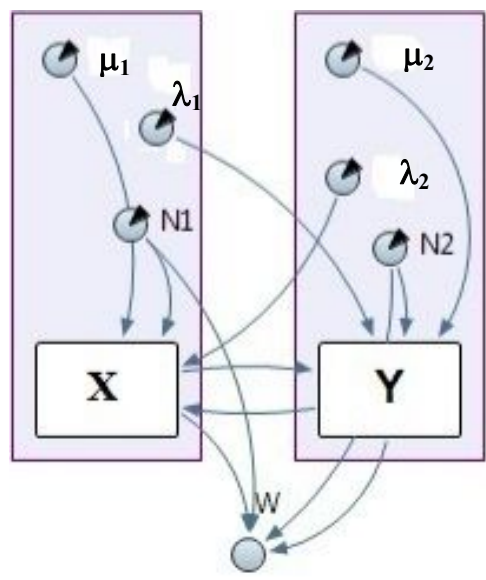

Рис. 2. Схема реалізації моделі рівнянь у середовищі AnyLogic

Інтерпретувати отримані дані можна наступним чином. Якщо припустити, що розглядається тактичний епізод оборони взводного опорного пункту від втричі переважаючих сил, а одиницею 
виміру часу прийнята доба, то, наприклад, для постійної інтенсивності відновлення $\mu 1=0,3$ після близько 4-х годин бою сторони зрівняються у чисельності (при цьому за системою рівнянь (10) отримані дані можуть бути перевірені).

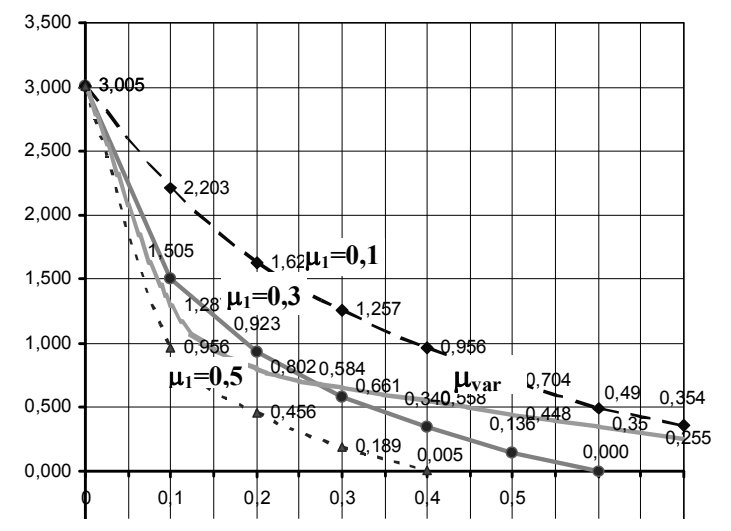

Рис. 3. Характер зміни співвідношення W протягом бою у залежності від інтенсивності відновлення чисельності сторони $x$

Це пояснюється постійним надходженням резервів до сторони $x$, і їх відсутністю у сторони $y$ (хоча сторона $y$ i володіє у 1,5 рази вищою інтенсивністю вражаючої дії). Логічним $\epsilon$ припущення про те, що сторона $y$ в такому разі відмовиться від подальших наступальних дій.

Звісно, наведений приклад $\epsilon$ умовним i приведений лише для демонстрації можливості варіювання параметру $\mu$, що значно більше відповідає реаліям бойових дій. Підкреслимо, що в цьому випадку важлива саме можливість змін параметрів типу $\lambda$ та $\mu$ протягом часу, тобто разом 3 поточними змінами $x$ та $y$ в процесі чисельного інтегрування. Це природнім чином дозволить урахувати, як вже було згадано, неоднорідність угруповань протиборчих сторін. Так, наприклад, зміна параметру $\lambda$ протягом бою (бойових дій), може свідчити про послідовне застосування артилерії, озброєння бойових машин, стрілецького озброєння тощо. Іншими словами, такий підхід до модифікації рівнянь динаміки бою представляє достатньо широкій арсенал засобів для їх перетворення і застосування у новій якості. При цьому коректність такого перетворення (модифікації) передбачає, зокрема, і необхідність урахування відповідних положень теорії диференціальних обчислень (в частині, що стосується перевірки стійкості отриманих рішень).

\section{Висновки й перспективи подальших досліджень}

Потреба органів військового управління та оперативних штабів різних рівнів у моделях, які дозволяють оперативно та достатньо адекватно прогнозувати можливий хід та результати бойових дій, обумовлює необхідність всебічного розгляду особливостей представників такого широкого класу моделей, якими $є$ аналітичні моделі. Особливе місце у цьому класі займають так звані моделі «динаміки середніх», побудовані на базі різних модифікацій рівнянь Осипова-Ланчестера.

Інтерес до методів та моделей динаміки середніх, який простежується за регулярними публікаціями у військових періодичних виданнях, свідчить про дієздатність такого апарату для питань прогнозування можливого ходу та результатів бойових дій. До переваг такого підходу можна віднести ясний фізичний зміст складових, які можуть входити у різні модифікації рівнянь (наслідком чого є можливість зрозумілим чином інтерпретувати отримані результати), оперативність отримання результатів та контрольованість проведення розрахунків. Оперативність та контрольованість процесу моделювання за складеними диференційними рівняннями можуть бути досягнути лише 3 використанням сучасних середовищ моделювання, оскільки більшість варіантів рівнянь Ланчестера 3 урахуванням відновлення (поновлення) озброєння (особового складу), змінної інтенсивності потоків подій (наприклад - уражаючої дії зразків озброєння) або складні для суто аналітичного вирішення, або взагалі його не мають і потребують використання методів чисельного інтегрування складених систем рівнянь.

До важливих обмежень моделей динаміки середніх слід віднести припущення про однорідність складу протиборчих угруповань. Таке обмеження обумовлене, насамперед, марківською природою методу. Неоднорідність складу угруповань, а також змінна інтенсивність надходження резервів до угруповань протягом бойових дій можуть бути ураховані шляхом варіювання відповідних коефіцієнтів у складених системах рівнянь. Використання змінних коефіцієнтів у системах диференційних рівнянь в процесі їх чисельного інтегрування потребує дослідження стійкості отриманих рішень (за Ляпуновим), а також використання сучасних середовищ моделювання 3 реалізованими у них алгоритмами чисельного інтегрування. У статті приведений приклад аналітичного розв'язання системи рівнянь Ланчестера 3 оцінкою стійкості рішення для постійних коефіцієнтів, а також результати вирішення тієї ж системи чисельним методом у середовищі AnyLogic для постійних та змінних коефіцієнтів інтенсивності поповнення чисельності угруповань. Результати розрахунків підтвердили збіжність результатів аналітичного i чисельного вирішення складеної системи рівнянь, що дає змогу розглядати використання змінних коефіцієнтів як достатньо перспективний напрямок модифікації рівнянь ,Ланчестера для опису динаміки бою. Такий підхід, на наш погляд, дозволить наблизити постановочну частину моделей до реалій бойових дій, а отримані 
результати характеризуватимуться більшою достовірністю.

Перспективою подальших досліджень вважається детальне дослідження топології ланчестерських моделей, яка приведена, зокрема, у [1], з метою оцінювання можливості модифікації різних варіантів рівнянь приведеним у статті способом. Важливими у цьому контексті питаннями залишаються наступні. По-перше, це питання використання змінних коефіцієнтів, яке передбачає необхідність розгляду застосування по відношенню до нестаціонарних систем методів, справедливих для стаціонарних систем (наприклад - методу «заморожування коефіцієнтів»). Такий підхід, хоча i значно спрошує дослідження згаданих систем рівнянь, не має достатньо строгого теоретичного обгрунтування. У той же час, за поглядами деяких фахівців, правомірність застосування методу «заморожування коефіцієнтів» у значній мірі залежить від того, чи знаходиться система у межах області стійких рішень, при цьому така система рівнянь не залежить від характеру зміни самих коефіцієнтів.
По-друге, це питання визначення таких коефіцієнтів як функцій часу. За їх допомогою можуть бути ураховані різноманітні особливості ведення бойових дій (поповнення чисельності угруповань або надходження резервів, матеріально-технічних засобів, зміна інтенсивності ураження противника при зосереджені або переносі вогню тощо). Тобто, в такому випадку самі коефіцієнти стають об'єктами дослідження, що дозволяє вести мову про комбіноване використання декількох методів. Так, наприклад, достатньо перспективним представляється застосування (для попереднього обчислення характеру змін у часі обраних коефіцієнтів) методів регресійного аналізу або імітаційного моделювання. Встановлені таким чином функціональні залежності можуть бути достатньо обгрунтовано застосовані у вигляді змінних коефіцієнтів у модифікаціях рівнянь Ланчестера. Це, безумовно, слугуватиме на користь більшої довіри до отриманих за їх допомогою результатів.

\section{Лimepamypa}

1. Митюков Н.В. К вопросу о типологии ланчестерских моделей / Н.В. Митюков // Круг идей: междисциплинарные подходы в исторической информатике. - М., 2008. - С. 375-399. 2. Брезгин В.С. Уравнения динамики боевых потенциалов противоборствующих группировок / В.С. Брезгин, А.И. Буравлев // Вооружение и экономика. - М., 2011. №1(13). - C.59-65.

\section{ПРИМЕНЕНИЕ МОДИФИЦИРОВАННЫХ УРАВНЕНИЙ ДИНАМИКИ СРЕДНИХ ДЛЯ ОПЕРАТИВНОГО ПРОГНОЗИРОВАНИЯ ХОДА И РЕЗУЛЬТАТОВ БОЕВЫХ ДЕЙСТВИЙ}

3. Вентцель Е.С. Исследование операций. - М., 1972. 552 с. 4. Котляров В.П. Методичний підхід до аналітичного розв'язання системи диференціальних рівнянь, які описують динаміку зміни чисельності протиборчих угруповань із урахуванням їх поповнення / В.П. Котлярів // Зб. наук. пр. ЦНДІ ЗС України. - К., 2013. - № 4(66). - C. 32-36.

\footnotetext{
Борис Леонидович Бутвин (доктор технических наук, профессор)

Александр Александрович Мачкин (кандидат технических наук, с. н. с.) Алексей Иванович Соломицкий (кандидат военных наук, с. н. с.)
}

\section{Центральный научно-иследовательский институт Вооруженных Сил Украины, Киев, Украина}

Статья посвящена рассмотрению особенностей применения уравнений динамики средних для оперативного прогнозирования хода и результатов боевых действий. Различные топологии уравнений Ланчестера могут быть использованы в качестве инструмента прогнозных расчетов, принимая во внимание оперативность получения результатов и ясный физический смысл составляющих таких уравнений. Однако, к важным ограничения моделей динамики средних следует отнести допущение про однородность состава противоборствующих группировок. Неоднородность состава группировок, а также переменная интенсивность поступления резервов в группировки на протяжении боевых действий могут быть учтены путем варьирования соответствующих коэффициентов в составленных системах уравнений. Использование переменных коэффициентов в системах дифференциальных уравнений в процессе их численного интегрирования требует оценки устойчивости полученных решений по Ляпунову. Сохранение оперативности осуществления прогнозных расчетов по модифицированным уравнениям Ланчестера возможно при условии использования современных сред моделирования с реализованными в них алгоритмами численного интегрирования. B статье приведен пример аналитического решения системь уравнений Ланчестера с оценкой устойчивости решения для постоянных коэффициентов, а также результаты решения этой же системь численным методом в среде AnyLogic для постоянных и переменных коэффищиентов интенсивности пополнения численности группировок. Подтвержденная сходимость результатов позволила в качестве вывода предложить использование модификации уравнений Ланчестера с переменными коэффициентами и одновременной Modern Information Technologies in the Sphere of Security and Defence $\mathcal{N}$ o 2(35)/2019 ISSN2311-7249(Print)/ISSN 2410-7336(Onfine) 119 
проверкой устойчивости их решений для приближения такого описания к реалиям боевых действий и повышения достоверности полученных результатов.

Ключевые слова: метод динамики средних; уравнения Ланчестера; динамика боевых действий.

\title{
THE USE OF MODIFIED EQUATION OF DYNAMICS OF MEDIUM FOR OPERATIVE FORECASTING OF THE COURCE AND RESULTS OF THE COMBAT ACTIONS
}

\author{
Borys Butvin (Doctor of Technical Sciences, Professor) \\ Olexander Mashkin (Candidate of Technical Sciences, Senior Researcher) \\ Olexii Solomitskii (Candidate of Military Sciences, Senior Researcher)
}

\section{Central Scientific Research Institute of the Armed Forces of Ukraine, Kyiv, Ukraine}

The article is devoted to the consideration of the peculiarities of the use of equations of dynamic of the medium for the operational forecasting of the course and the results of combat operations. Different topologies of the equations of Lancaster can be used as a tool for predictive calculations, taking into account the efficiency of obtaining results and the clear physical content of the components of such equations. But, to the important limitations of the models of dynamics of medium should include assumptions about the homogeneity of the staff of the opposing groups. The heterogeneity of the staff of the groups, as well as the variable intensity of the receipt of reserves to the groups during combat operations, can be taken into account by varying the corresponding coefficients in the complex systems of equations. The use of variable coefficients in systems of differential equations in the course of their numerical integration requires an evaluation of the stability of the solutions obtained by Liapunov. Preservation of the efficiency of the implementation of predictive calculations based on modified equations of Lancaster is possible with the use of modern simulation environments with the numerical integration algorithms implemented in them. The article gives an example of an analytical solution of the system of the Lancaster equations with the estimation of the stability of the solution for constant coefficients, as well as the results of the solution of the same system by a numerical method in the AnyLogic environment for constant and variable coefficients of the intensity of replenishment of the grouping. The confirmed convergence of the results allowed us to suggest the use of the modification of the systems of the equations of Lancaster with variable coefficients with the simultaneous assessment of the stability of their solutions to approximate this description to the realities of combat operations and increase the reliability of the results.

Keywords: dynamics method of medium; equation of Lancaster; the dynamics of combat actions.

\section{References}

1. Mytiukov N.V. (2008), On the question of the typology of Lanchester models. [K voprosu o topologii lanchesterskikh modeley]. Circle of ideas: interdisciplinary approaches in historical computer science, Moscow, pp. 375-399. 2. Brezgin V.S., Buravlev A.I. (2011), Equations of dynamics of combat potentials of confrontational groups. [Uravneniya dinamiki boyevykh potentsialov protivoborstvuyushikh gruppirovok], Armament and economy, No. 1(13), pp. 59-65. 3. Ventzel E.S. (1972), Investigation of operations. [Issledovaniye operatsiy], Soviet radio, Moscow, $552 \mathrm{p}$.
4. Kotliarov V.P. (2013), Methodical approach to the analytical solution of the system of differential equations, which describe the dynamics of change in the number of opposing groups, taking into account their replenishment. [Metodychnyy pidkhid do analitychnoho rozv'yazannya systemy dyferentsial'nykh ryvnyan', yaki opysuyut' dynamiku zminy chysel'nosti protyborchykh uhrupovan' iz urakhuvannyam yikh popovnennya], Coll. of scienc. works of CSRI of the Armed Forces of Ukraine, Kiev, No. 4 (66). pp. 32-36. 